\title{
Identification of Baking Expansion Phases of Leavened Dough Using an Experimental Approach
}

\author{
Antoni Miś $^{1}$ - Agnieszka Nawrocka ${ }^{1} \cdot$ Dariusz Dziki $^{2}$
}

Received: 28 April 2015 / Accepted: 28 December 2015 / Published online: 22 January 2016

(C) The Author(s) 2016. This article is published with open access at Springerlink.com

\begin{abstract}
A measurement system was designed to study changes in the volume, pressure, and viscosity of dough leavened by baking powder during model baking. Analysis of the volume changes demonstrated two baking stages, i.e. dough expansion and crumb shrinking. Through the analysis of pressure and viscosity extremes, the expansion stage was divided into five phases: stress relaxation (R) characterised by a mild pressure decline; gluten matrix softening (S), during which the decrease in viscosity is accompanied by a gradual pressure rise contributing to substantial dough expansion (by $\sim 54 \%$ ); starch gelatinisation and protein aggregation $(\mathrm{G})$ characterised by rapidly increasing viscosity; gas bubble opening $(\mathrm{O})$ reflecting a rapid pressure reduction; and boiling of water in dough (B), which ends at initiation of crumb shrinking. The study showed that enrichment of the dough with carob fibre increased the contribution of phases $\mathrm{S}$ and $\mathrm{O}$ to dough expansion at the cost of phase G. A similar contribution of the expansion phases was reported for the Bombona cultivar, which exhibits the highest gluten content. In contrast, the Finezja and Katoda cultivars, which have a lower gluten level, were characterised by an approximately two-fold higher impact of phase $\mathrm{G}$ on the increase in dough expansion. The results indicated that the developed method for identification of baking expansion phases of leavened
\end{abstract}

Antoni Miś

a.mis@ipan.lublin.pl

Institute of Agrophysics, Polish Academy of Sciences, Doświadczalna 4, 20-290 Lublin, Poland

2 Department of Thermal Technology, University of Life Sciences, Doświadczalna 44, 20-280 Lublin, Poland dough can be useful in baking characteristics of raw materials and bakery additives.

Keywords Leavened dough · Fibre-rich additions · Wheat cultivars · Model baking · Expansion phases · Baking characteristics

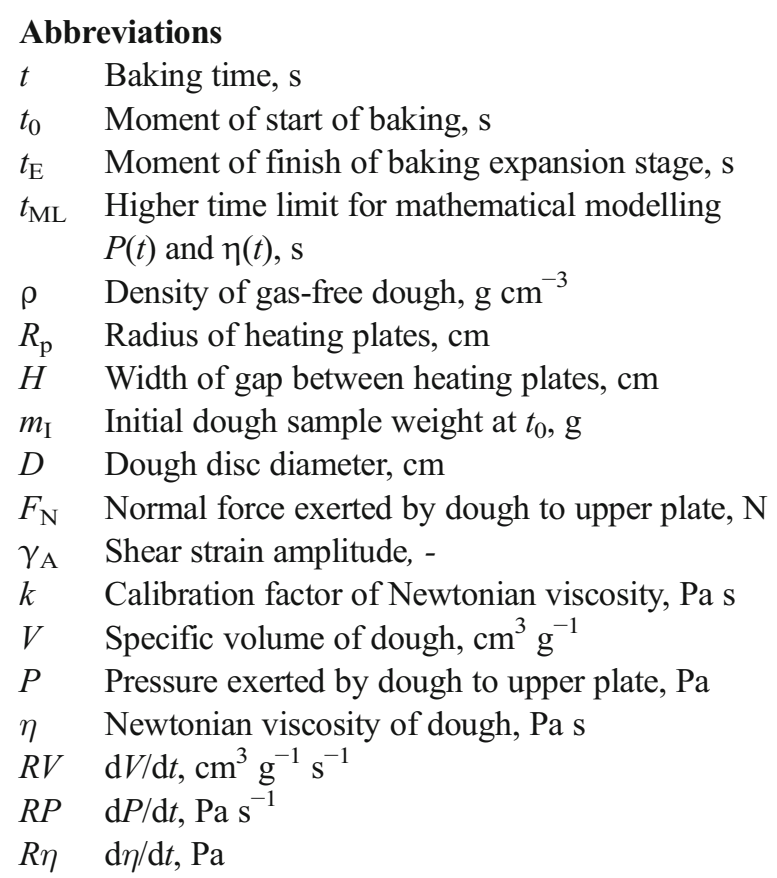

\section{Subscripts}

Min Minimum

Max Maximum 


\section{Introduction}

A baking temperature induces a variety of physical and chemical processes that transform viscous-liquid dough into bakery product with solid and cellular-structured crumb (Mondal and Datta 2008). The most readily observable symptom of these processes is dough expansion accompanied by externally invisible changes in its cellular structure. In chemically leavened dough, expansion is possible thanks to accumulation of high amounts of $\mathrm{CO}_{2}$ in aqueous phase of the dough. The gas is produced at the stage of dough mixing, when the leavening agent, mostly sodium bicarbonate, reacts with water (Bellido et al. 2009). During baking, the temperature rise increases $\mathrm{CO}_{2}$ saturation, forcing its diffusion from the liquid to gaseous phase of dough. Consequently, air bubbles serving as nucleation sites are filled with carbon dioxide and their volume gradually increases. During the growth, gas bubbles coalesce and, as a result, become more diverse in terms of size, and their number is substantially reduced (Babin et al. 2006). In addition to the amount of the gas accumulated in the bubbles, the increase in its pressure induced by the rising temperature enhances gas bubble expansion. Inhibition of expansion begins at the time of cell opening, which leads to rapid release of the gases and a simultaneous decline in their pressure in dough (Singh and Bhattacharya 2005). At the end of baking when the dough temperature in the peripheral zone reaches the water boiling point, the produced water vapour pressure is an additional force maintaining the further dough expansion process until the end of the thermosetting of the crumb cellular structure (Wang and Sun 1999). Continuation of baking is associated with formation of an increasingly thicker bread crust and considerable drying of crumb. Consequently, the loaf volume begins to decrease (Rouillé et al. 2010; Sommier et al. 2005; Wagner et al. 2007).

Besides the above-mentioned physical and structural changes, chemical transformations take place, with starch gelatinisation (Besbes et al. 2014; Chevallier et al. 2000) and gluten protein aggregation (Singh 2005) as the most important processes. During gelatinisation, starch granules absorb water and change in size and shape due to swelling and crystal melting (Fessas and Schiraldi 2000). The gluten proteins, i.e. gliadins and glutenins, form a continuous three-dimensional network, which ensures viscoelastic properties of the dough and determines the proper transformation thereof into crumb. During baking, the gluten network is strengthened through formation of additional cross-links, mainly disulphide bonds (Wieser 2007), which ultimately leads to thermosetting of the bread crumb. The major symptoms of thermal modifications include an increase in molecular weights of gluten proteins and their reduced solubility (Schofield et al. 1983; Singh 2005).

The starch and protein transformations as well as changes in dough temperature and moisture have a significant effect on dough rheology during baking. At the early stages of baking, dough consistency gradually softens as an immediate effect of gluten protein weakening by an increasing temperature (Ahmed 2015). When dough reaches a temperature of $55-60{ }^{\circ} \mathrm{C}$ initiating the processes of starch gelatinisation and gluten protein aggregation, viscosity increases rapidly (Rouillé et al. 2010; Singh and Bhattacharya 2005) until dough reaches ca. $75^{\circ} \mathrm{C}$. A further temperature rise leads to a decrease in dough viscosity (Dreese et al. 1988; Vanin et al. 2010) related to disruption of swollen starch granules and melting of remaining crystallites (Ahmed et al. 2013; Keetels et al. 1996). No decline in viscosity is observed when the moisture of the crust zone decreases below $37 \%$ and a long-lasting plateau of viscosity is evident (Vanin et al. 2013). In the final baking stage when dough reaches the water boiling point, viscosity increases proportionally to the rate of the decrease in the water content.

Given the considerable complexity of the discussed dough/crumb transitions, in vivo investigations of their course still pose many difficulties due to lack of appropriate measurement tools. Researchers usually have equipment suitable for tracing one selected element of these transitions. Changes in the dough volume were typically approximated by measurements of the dough section area (Rouillé et al. 2010; Sommier et al. 2005) or loaf height (Grenier et al. 2010; Pérez-Nieto et al. 2010) using a digital video camera. Measurements of pressure in gas bubbles posed greater difficulties. Sommier et al. (2005) and Grenier et al. (2010) used pressure sensors inserted into dough before shaping. However, during baking, the location of the sensor was changing thereby considerably disrupting the pressure reading. In contrast, analyses of the dough viscosity are based on more precise measurement tools such as the dynamic thermomechanical analyser (DMA). They are, however, performed on unleavened dough (Fessas and Schiraldi 2000; Rouillé et al. 2010; Vanin et al. 2013; Wang and Sun 1999), while the development of the dough cellular structure and its transformation into crumb is an integral part of baking. Additionally, for obtaining more comprehensive data it is desirable to perform the measurements of dough volume, pressure and viscosity changes during baking process simultaneously and on the same dough sample.

The aim of the study was to use the developed measurement system for assessment of the effect of technological (dietary fibre enrichment) and genotypic (wheat cultivars) factors on volume, pressure, and viscosity changes during model baking of chemically leavened dough and for identification of dough expansion phases that can be important in characterisation of the baking quality of raw materials and bakery additives. 


\section{Materials and Methods}

\section{Materials}

Commercial wheat bread flour (CF), type 750 (Cereal Mill, Piaski, Poland), and its blend with addition of carob fibre (CF + C) $(5 \% w / w)$ or oat wholemeal $(\mathrm{CF}+\mathrm{O})(15 \% w / w)$ were used in the investigations of fibre enrichment effects. The chemical composition and rheological characteristics of these additives were described in the previous papers (Miś and Dziki 2013; Nawrocka et al. 2015, 2016). In turn, investigations of the genotypic background were conducted on laboratory-milled flour (Quadrumat Junior, Brabender, Duisburg, Germany) from four Polish wheat cultivars of winter form: Finezja (FIN), and spring form: Bombona (BOM), Katoda (KAT) and Zebra (ZEB) (Danko Plant Breeders, Laski, Poland). The standard characteristics of the baking quality of the analysed material are shown in Table 1. The amount of dry gluten, gluten water absorption, and gluten index were determined in accordance with ICC standard no. 155 (ICC 1994). The amylolytic activity of the flour was assessed by determination of the falling number in accordance with ICC standard no. 107 (ICC 1995), the flour water absorption, dough development time, stability, and the degree of dough softening were determined farinographically in accordance with ICC standard no. 115/1 (ICC 1992).

\section{Preparation of Dough}

Preparation of dough was performed with a Farinograph-E equipped with a mixer S 50 with sigma blades (model 810114, Brabender, Duisburg, Germany). The dough was mixed using $50 \mathrm{~g}$ flour or a blend (on a $14 \%$ moisture basis), $1.5 \mathrm{~g}$ baking powder (Dr. Oetker Poland, Gdańsk, Poland), and water in an amount specified by the farinograph (Table 1) until $500 \mathrm{FU}$ dough consistency was achieved. The mixing time was $5 \mathrm{~min}$. A disc-shaped sample was cut out of the dough rolled out to a thickness of $7 \mathrm{~mm}$ using an 18-mm-diameter cork borer; for dough proving, the sample was left in a water vapour chamber at a constant temperature of $22^{\circ} \mathrm{C}$ for $30 \mathrm{~min}$.

\section{Procedure of Model Baking}

Model baking was performed using a prototype measurement system designed in the Institute of Agrophysics PAS, Lublin. The concept scheme of the measurement system is shown in Fig. 1a. It comprised a heating module (ZPPH, Czerwionka, Poland), a rotation-oscillation rheometer (StressTech, Reologica Instruments AB, Lund, Sweden), and four laser sensors of the sample displacement (OptoNCDT 1300, Micro-Epsilon, Ortenburg, Germany). The heating module was composed of two parallel disc-shaped heating plates with a fixed lower plate and a mobile upper plate attached to the rheometer rotor. The heating power of both plates controlled independently by an external regulator allowed increasing their temperature at a rate of $1^{\circ} \mathrm{C} \mathrm{s}^{-1}$ in the range from 22 to $130{ }^{\circ} \mathrm{C}$ (Fig. 2a). Due to the small size of a dough specimen, the temperature sensor was not placing inside the dough disc because it could cause significant disturbances during dough expansion measurements. It can be assumed that the dough temperature differs slightly from the temperature of the heating plates within the range from 22 to $100{ }^{\circ} \mathrm{C}$, and the phenomenon of boiling water prevents further increase of dough temperature. The plates were covered with Teflon, which prevented dough from sticking. However, the strength of dough adhesion to the Teflon surface was markedly greater than the peak torque applied during measurements of dough viscosity. Using a rheometer, rotating-oscillating movement of the upper plate was initiated and changes in viscosity were determined as a function of baking time $t$ by measurements of the shear strain amplitude $\gamma_{\mathrm{A}}(t)$, and dough pressure was

Table 1 Results of standard evaluation of baking quality of commercial bread flour without (CF) or with addition of carob fibre (CF $+\mathrm{C})$ or oat wholemeal $(\mathrm{CF}+\mathrm{O})$ and flours from laboratory milling of grain of wheat cultivars: Finezja (FIN), Bombona (BOM), Katoda (KAT) and Zebra (ZEB)

\begin{tabular}{lccccccc}
\hline Standard quality indices & \multicolumn{2}{c}{ Experimental combinations } & & & \\
\cline { 2 - 7 } & CF & CF + C & CF + O & FIN & BOM & KAT & ZEB \\
\hline Dry gluten quantity (\%) & $8.3 \pm 0.3^{\mathrm{b}}$ & $8.3 \pm 0.1^{\mathrm{b}}$ & $6.3 \pm 0.2^{\mathrm{a}}$ & $9.5 \pm 0.1^{\mathrm{c}}$ & $15.2 \pm 0.1^{\mathrm{f}}$ & $13.2 \pm 0.1^{\mathrm{d}}$ & $13.8 \pm 0.1^{\mathrm{e}}$ \\
Gluten water absorption (\%) & $176.7 \pm 1.4^{\mathrm{a}}$ & $176.2 \pm 1.1^{\mathrm{a}}$ & $177.9 \pm 2.4^{\mathrm{a}}$ & $196.5 \pm 2.9^{\mathrm{bc}}$ & $200.5 \pm 2.4^{\mathrm{c}}$ & $195.8 \pm 1.1^{\mathrm{b}}$ & $198.4 \pm 1.8^{\mathrm{bc}}$ \\
Gluten index (\%) & $97.9 \pm 0.3^{\mathrm{e}}$ & $96.7 \pm 0.2^{\mathrm{de}}$ & $97.2 \pm 1.0^{\mathrm{de}}$ & $95.1 \pm 1.1^{\mathrm{d}}$ & $83.4 \pm 0.3^{\mathrm{a}}$ & $92.5 \pm 0.4^{\mathrm{c}}$ & $89.9 \pm 2.1^{\mathrm{b}}$ \\
Falling number (s) & $213 \pm 9^{\mathrm{a}}$ & $215 \pm 6^{\mathrm{a}}$ & $225 \pm 4^{\mathrm{a}}$ & $544 \pm 14^{\mathrm{b}}$ & $707 \pm 19^{\mathrm{c}}$ & $527 \pm 13^{\mathrm{b}}$ & $674 \pm 36^{\mathrm{c}}$ \\
Flour water absorption (\%) & $57.2 \pm 0.2^{\mathrm{b}}$ & $59.7 \pm 0.4^{\mathrm{d}}$ & $58.3 \pm 0.2^{\mathrm{c}}$ & $56.1 \pm 0.4^{\mathrm{a}}$ & $63.5 \pm 0.1^{\mathrm{g}}$ & $61.0 \pm 0.1^{\mathrm{e}}$ & $61.9 \pm 0.1^{\mathrm{f}}$ \\
Dough development (min) & $2.0 \pm 0.3^{\mathrm{a}}$ & $1.7 \pm 0.3^{\mathrm{a}}$ & $2.0 \pm 0.3^{\mathrm{a}}$ & $1.9 \pm 0.2^{\mathrm{a}}$ & $8.0 \pm 0.3^{\mathrm{b}}$ & $12.2 \pm 0.8^{\mathrm{c}}$ & $8.1 \pm 0.6^{\mathrm{b}}$ \\
Dough stability (min) & $2.6 \pm 0.1^{\mathrm{a}}$ & $1.4 \pm 0.2^{\mathrm{a}}$ & $2.1 \pm 0.4^{\mathrm{a}}$ & $3.0 \pm 0.2^{\mathrm{a}}$ & $11.3 \pm 0.9^{\mathrm{b}}$ & $19.1 \pm 1.3^{\mathrm{d}}$ & $15.0 \pm 1.1^{\mathrm{c}}$ \\
Dough softening (F.U.) & $99 \pm 5^{\mathrm{d}}$ & $117 \pm 3^{\mathrm{f}}$ & $111 \pm 5^{\mathrm{ef}}$ & $84 \pm 3^{\mathrm{c}}$ & $55 \pm 5^{\mathrm{b}}$ & $31 \pm 6^{\mathrm{a}}$ & $39 \pm 6^{\mathrm{a}}$ \\
\hline
\end{tabular}

Values in the same row followed by different superscript letters are significantly different from each other $(\alpha=0.05)$ 


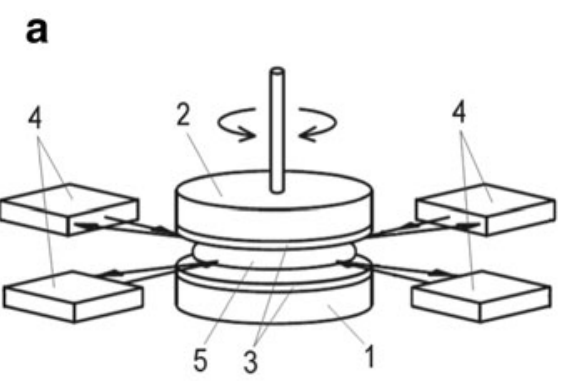

Fig. 1 Schematic diagram of the measuring set: 1 - fixed heating plate, 2 - rotating-oscillating heating plate, 3 - Teflon covering, 4 - laser displacement sensors, 5 - disc-shaped dough sample (a), and geometry

determined by measuring normal force $F_{\mathrm{N}}(t)$ exerted by the dough on the upper plate. Dough lateral expansion was monitored with four laser sensors placed around the measurement gap in the rheometer. They measured the diameter $D(t)$ of the dough disc in the middle of its height with an accuracy of $\pm 10 \mu \mathrm{m}$.

After the dough proving period, the dough disc was weighed with an accuracy of $0.01 \mathrm{~g}$ and placed in the gap with a width of $H=0.5 \mathrm{~cm}$ between the heating plates with a radius of $R_{\mathrm{p}}=2.5 \mathrm{~cm}$ and temperature stabilised at $22 \pm 1{ }^{\circ} \mathrm{C}$. As the test began, the plate temperature was increased from 22 to $130{ }^{\circ} \mathrm{C}$ in accordance with the characteristics shown in Fig. 2a. During the model baking, constant torque amplitude of $82 \mathrm{mN} \mathrm{m}$ (shear stress of $25 \mathrm{~Pa}$ at $R_{\mathrm{p}}=2.5 \mathrm{~cm}$ ) was maintained for induction of low range oscillations of the upper

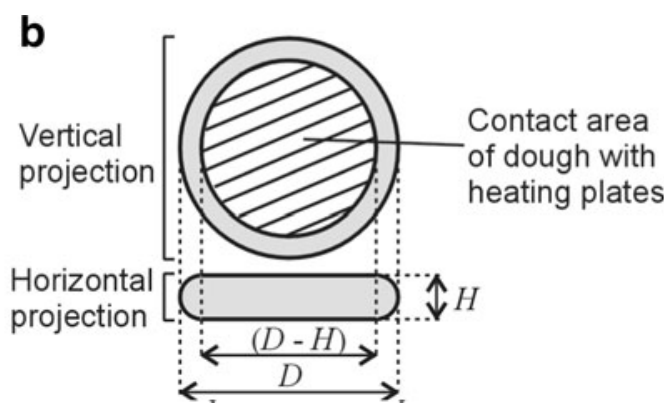

of dough sample during baking: $H$ - Width of gap between heating plates, $D$ - Dough disc diameter (b)

plate and constant oscillation frequency $\left(10 \mathrm{~s}^{-1}\right)$ was ensured. Simultaneously, at the same frequency $f=10 \mathrm{~s}^{-1}$, the $D(t)$, $F_{\mathrm{N}}(t)$, and $\gamma_{\mathrm{A}}(t)$ were recorded and converted into values of specific volume $V(t)$, also named shortly as volume, pressure $P(t)$, and viscosity $\eta(t)$ of the dough using the formulas presented below:

$V(t)=1 / 12 \cdot \pi \cdot H \cdot\left[2 D(t)^{2}+(D(t)-H)^{2}\right] / m_{I}, \mathrm{~cm}^{3} \cdot g^{-1}$
$P(t)=F_{N}(t) /\left[10^{-6} \cdot \pi \cdot((D(t)-H) / 2)^{2}\right], P a$
$\eta(t)=1 / \gamma_{A}(t) \cdot R_{p}{ }^{4} /((D(t)-H) / 2)^{4} \cdot \rho \cdot V(t) \cdot k, P a \cdot s$

where: $m_{\mathrm{I}}$ is the initial dough sample weight, $k$ is the calibration factor for converting the measurement results
Fig. 2 Characteristics of temperature of heating plates (a), and exemplary measurement data for commercial bread flour (CF) reflecting changes in chemically leavened dough volume (b), pressure (c) and viscosity (d) during a single model baking test
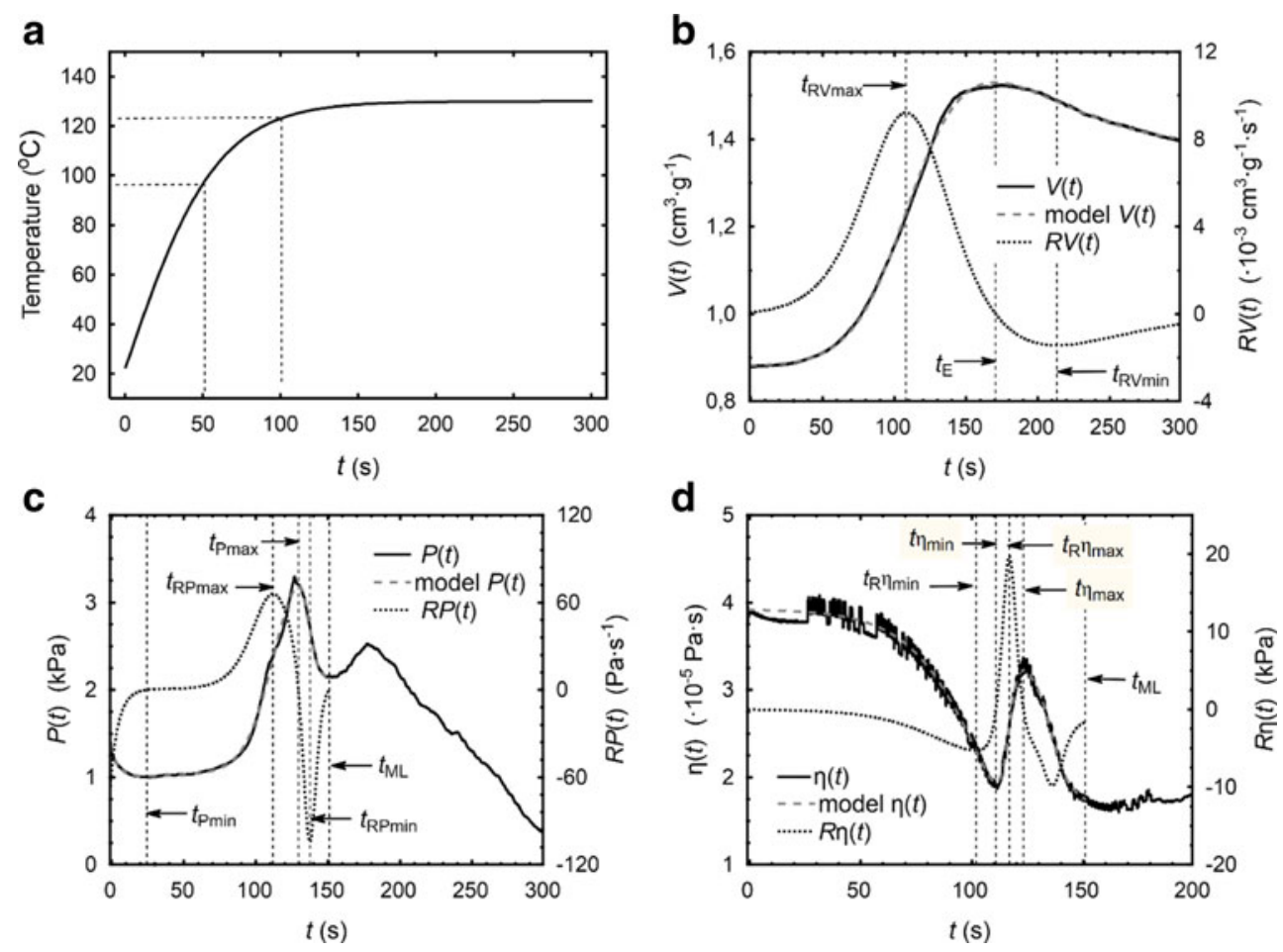
into units of the Newtonian viscosity, and $\rho$ is the density of the non-gaseous dough phase.

The development of Formulas (1), (2), and (3) was based on the following assumptions:

1. During the expansion test, the dough disc has a shape of a barrel (Fig. 1b), whose height is limited by the width of gap $H$ between the heating plates, and the lateral sides of the barrel are $H$-diameter semicircles formed as a result of a uniform pressure distribution in the dough sample. Hence, the dough surface in contact with the heating plate was equal to the area of a circle with a radius $(D(t)-H) / 2$.

2. Pressure $P(t)$ measured on the dough surface corresponds to the difference between the pressure inside the gas bubbles and the external pressure, which is a sum of atmospheric and hydrostatic pressures, and the pressure related to the rheological properties of dough, e.g. surface tension, viscosity yield, and elasticity. In this approach, $P(t)$ is the direct cause of dough expansion and its value equals the product of non-gaseous phase dough viscosity and the rate of gas bubble expansion.

3. Viscosity $\eta(t)$ determined in an oscillatory shear test at a constant torque amplitude and constant oscillation frequency is inversely proportional to the $\gamma_{\mathrm{A}}(t)$. Due to dough expansion, the changing diameter and density of the sample exert an impact on the result of viscosity measurement. This effect is compensated by using the factor in the form of $R_{\mathrm{p}}{ }^{4} /((D(t)-H) /$ $2)^{4} \rho V(t)$. The gas-free dough density $\rho$ was calculated assuming the density of the wheat flours, the carob fibre, the oat wholemeal, and the baking powder equal to $1.5 \mathrm{~g} \mathrm{~cm}^{-3}$. The calculated values of the density $\rho$ for the experimental combinations ranged from $1.217 \mathrm{~g} \mathrm{~cm}^{-3}$, for cultivar Bombona, to $1.229 \mathrm{~g} \mathrm{~cm}^{-3}$, for cultivar Finezja. They corresponded well with those ones measured experimentally by Chin and Campbell (2005) and Elmehdi et al. (2004).

The calibration factor $k$ was determined empirically in 200 -s creep tests on dough prepared in an identical way as for the baking tests maintaining a constant dough temperature of $22{ }^{\circ} \mathrm{C}$ and a constant shear stress of $25 \mathrm{~Pa}$. The data obtained were described using the six-parameter Burger model (Miś 2011), and the measurement result of Newtonian viscosity $\eta_{0}$ was regarded as a calibration standard.

All stages of the dough preparation and baking tests were made in four replications for all experimental combinations.

\section{Statistical Analyses}

Analyses of non-linear regression and variance of measurement data were conducted using the software Statistica v.10, PL (StatSoft Inc., Tulsa, USA). For objective characterisation of the changes in volume $V(t)$, pressure $P(t)$, and viscosity $\eta(t)$ of the dough (Fig. 2b, c, d) as a function of baking time $t$, non-linear regression models composed of the sigmoid and exponential functions were used in the following form:

$V(t)=f_{1}(t)-f_{2}(t)$

$P(t)=f_{1}(t)-f_{2}(t)+f_{3}(t)$

$\eta(t)=f_{1}(t)-f_{2}(t)+f_{4}(t)$

where: $f_{1}(t)=p_{f 11}+p_{f 12} \cdot\left(1+\exp \left(p_{f 13} \cdot\left(p_{f 14}-t\right)\right)\right)^{-1}$ $, f_{2}(t)=p_{f 21} \cdot\left(1+\exp \left(p_{f 22} \cdot\left(p_{f 23}-t\right)\right)\right)^{-1}, f_{3}(t)=p_{f 31}$ $\cdot \exp \left(-t \cdot p_{f 32}{ }^{-1}\right)+p_{f 33} \cdot t, f_{4}(t)=p_{f 41} \cdot\left(1+\exp \left(p_{f 42}\right.\right.$. $\left.\left.\left(p_{f 43}-t\right)\right)\right)^{-1}, p_{f 11}+p_{f 12}, \ldots, p_{f 43}$ - the model parameters.

Modelling of the changes' course in dough pressure and viscosity was limited to the expansion time range from $t_{0}$ to $t_{\mathrm{ML}}$ (Fig. 2c, d). Baking time $t>t_{\mathrm{ML}}$ initiated the phenomenon of dough water boiling characterised by hardly regular changes in the dough pressure, which prevented selection of an appropriate regression model. Viscosity measurements were disrupted by problems caused by times $t>t_{\mathrm{ML}}$. They were manifested by the fact that a longer baking time contributed to the loss of dough adhesive properties and to dough shrinking. Consequently, such dough did not adhere exactly to the plate surface and the slip phenomenon appeared, which definitely distorted the results of the measurement of the shear strain $\gamma_{\mathrm{A}}\left(t>t_{\mathrm{ML}}\right)$. Despite these limitations, the baking time interval from $t_{0}$ to $t_{\mathrm{ML}}$ was wide enough to analyse all relevant phases of dough expansion during model baking.

The fitting degree of the regression models (4), (5), and (6) to the measurement data (Fig. 2b, c, d) estimated with the coefficient of determination $R^{2}$ was high and reached over 0.99 . Hence, they were useful for calculation of the rate of changes in dough volume $(R V(t))$, pressure $(R P(t))$, and viscosity $(R \eta(t))$ according to the formulas: $R V(t)=\mathrm{d} V(t) / \mathrm{d} t$, $R P(t)=\mathrm{d} P(t) / \mathrm{d} t$, and $R \eta(t)=\mathrm{d} \eta(t) / \mathrm{d} t$. The extremes for the model functions (4), (5) and (6) and their derivatives were determined. The moments of occurrence of the extremes were referred to the time $t_{\mathrm{E}}$ of completion of the baking expansion stage when $V\left(t_{\mathrm{E}}\right)=V_{\max }$ (Table 2). They were used to identify the beginning and end of each of the proposed phases of baking expansion as shown in Fig. 3.

The significance of the differences between the experimental combinations was estimated using one-way analysis of variance (ANOVA) followed by Tukey's test $(\alpha=0.05)$. In all tables the results are presented as means \pm standard deviations of four replications. 
Table 2 Effect of experimental combinations on changes in dough volume, pressure and viscosity during model baking

\begin{tabular}{|c|c|c|c|c|c|c|c|}
\hline \multirow[t]{2}{*}{ Model baking indices } & \multicolumn{7}{|c|}{ Experimental combinations } \\
\hline & $\mathrm{CF}$ & $\mathrm{CF}+\mathrm{C}$ & $\mathrm{CF}+\mathrm{O}$ & FIN & BOM & KAT & ZEB \\
\hline \multicolumn{8}{|l|}{ Volume changes } \\
\hline$V\left(t_{0}\right)-1 / \rho\left(\times 10^{-3} \mathrm{~cm}^{3} \mathrm{~g}^{-1}\right)$ & $67 \pm 8^{\mathrm{b}}$ & $50 \pm 11^{\mathrm{a}}$ & $64 \pm 11^{\mathrm{ab}}$ & $61 \pm 3^{\mathrm{ab}}$ & $61 \pm 2^{\mathrm{ab}}$ & $58 \pm 2^{\mathrm{ab}}$ & $59 \pm 5^{\mathrm{ab}}$ \\
\hline$t_{\mathrm{E}}(\mathrm{s})$ & $172 \pm 4^{\mathrm{bc}}$ & $164 \pm 4^{\mathrm{a}}$ & $167 \pm 3^{\mathrm{ab}}$ & $179 \pm 4^{\text {cde }}$ & $176 \pm 1^{\mathrm{cd}}$ & $185 \pm 3^{\mathrm{e}}$ & $180 \pm 4^{\mathrm{de}}$ \\
\hline$V\left(t_{\mathrm{E}}\right)-V\left(t_{0}\right)\left(\times 10^{-3} \mathrm{~cm}^{3} \mathrm{~g}^{-1}\right)$ & $637 \pm 13^{\mathrm{bc}}$ & $580 \pm 17^{\mathrm{a}}$ & $735 \pm 20^{\mathrm{d}}$ & $591 \pm 31^{\mathrm{abc}}$ & $641 \pm 22^{\mathrm{c}}$ & $581 \pm 32^{\mathrm{a}}$ & $585 \pm 15^{\mathrm{ab}}$ \\
\hline$V\left(t_{\mathrm{E}}+100 \mathrm{~s}\right) / V\left(t_{\mathrm{E}}\right)-1(\%)$ & $-17.1 \pm 0.2^{\mathrm{bc}}$ & $-17.4 \pm 0.3^{\mathrm{ab}}$ & $-17.6 \pm 0.1^{\mathrm{ab}}$ & $-18.9 \pm 0.2^{\mathrm{a}}$ & $-16.6 \pm 1.0^{\mathrm{bc}}$ & $-15.6 \pm 1.5^{\mathrm{c}}$ & $-16.6 \pm 0.3^{\mathrm{bc}}$ \\
\hline$R V_{\max }\left(\times 10^{-5} \mathrm{~cm}^{3} \mathrm{~g}^{-1} \mathrm{~s}^{-1}\right)$ & $927 \pm 9^{\mathrm{ab}}$ & $971 \pm 29^{b}$ & $1175 \pm 31^{\mathrm{c}}$ & $851 \pm 68^{\mathrm{a}}$ & $1094 \pm 61^{\mathrm{c}}$ & $837 \pm 60^{\mathrm{a}}$ & $946 \pm 55^{\mathrm{ab}}$ \\
\hline$t_{\mathrm{RVmax}} / t_{\mathrm{E}}\left(\times 10^{-3}\right)$ & $634 \pm 9^{\mathrm{a}}$ & $633 \pm 12^{\mathrm{a}}$ & $650 \pm 6^{\mathrm{ab}}$ & $665 \pm 10^{\mathrm{b}}$ & $654 \pm 9^{\mathrm{ab}}$ & $671 \pm 10^{\mathrm{b}}$ & $658 \pm 6^{\mathrm{b}}$ \\
\hline$R V_{\min }\left(\times 10^{-5} \mathrm{~cm}^{3} \mathrm{~g}^{-1} \mathrm{~s}^{-1}\right)$ & $-139 \pm 5^{\mathrm{bc}}$ & $-125 \pm 7^{\mathrm{c}}$ & $-167 \pm 6^{\mathrm{a}}$ & $-149 \pm 10^{\mathrm{ab}}$ & $-132 \pm 11^{\mathrm{bc}}$ & $-121 \pm 16^{\mathrm{c}}$ & $-124 \pm 6^{\mathrm{c}}$ \\
\hline$t_{\mathrm{RV} \min } / t_{\mathrm{E}}\left(\times 10^{-3}\right)$ & $1269 \pm 23^{\mathrm{ab}}$ & $1345 \pm 24^{\mathrm{c}}$ & $1260 \pm 8^{\mathrm{ab}}$ & $1229 \pm 9^{\mathrm{a}}$ & $1344 \pm 17^{\mathrm{c}}$ & $1225 \pm 8^{\mathrm{a}}$ & $1287 \pm 35^{\mathrm{b}}$ \\
\hline \multicolumn{8}{|l|}{ Pressure changes } \\
\hline$P_{\min }(\mathrm{kPa})$ & $0.99 \pm 0.03^{\mathrm{a}}$ & $1.03 \pm 0.03^{\mathrm{ab}}$ & $1.00 \pm 0.07^{\mathrm{a}}$ & $1.20 \pm 0.05^{\mathrm{c}}$ & $1.16 \pm 0.03^{\mathrm{bc}}$ & $1.17 \pm 0.03^{\mathrm{c}}$ & $1.14 \pm 0.11^{\mathrm{bc}}$ \\
\hline$t_{\mathrm{Pmin}} / t_{\mathrm{E}}\left(\times 10^{-3}\right)$ & $140 \pm 10^{\mathrm{a}}$ & $149 \pm 10^{\mathrm{a}}$ & $122 \pm 14^{\mathrm{a}}$ & $274 \pm 14^{\mathrm{b}}$ & $335 \pm 19^{c}$ & $285 \pm 37^{\mathrm{b}}$ & $352 \pm 15^{\mathrm{c}}$ \\
\hline$P_{\max }(\mathrm{kPa})$ & $3.22 \pm 0.05^{\mathrm{ab}}$ & $2.79 \pm 0.21^{\mathrm{a}}$ & $3.71 \pm 0.18^{\mathrm{b}}$ & $3.67 \pm 0.21^{\mathrm{b}}$ & $3.69 \pm 0.38^{\mathrm{b}}$ & $3.58 \pm 0.34^{\mathrm{b}}$ & $3.74 \pm 0.28^{\mathrm{b}}$ \\
\hline$t_{\mathrm{Pmax}} / t_{\mathrm{E}}\left(\times 10^{-3}\right)$ & $752 \pm 10^{\mathrm{ab}}$ & $733 \pm 2^{\mathrm{a}}$ & $769 \pm 8^{\mathrm{b}}$ & $761 \pm 3^{\mathrm{ab}}$ & $743 \pm 6^{\mathrm{ab}}$ & $762 \pm 15^{\mathrm{ab}}$ & $756 \pm 29^{\mathrm{ab}}$ \\
\hline$t_{\mathrm{ML}} / t_{\mathrm{E}}\left(\times 10^{-3}\right)$ & $883 \pm 6^{\mathrm{abc}}$ & $900 \pm 4^{\mathrm{bc}}$ & $911 \pm 15^{\mathrm{bc}}$ & $878 \pm 14^{\mathrm{ab}}$ & $919 \pm 9^{c}$ & $857 \pm 28 \mathrm{a}$ & $884 \pm 22^{\mathrm{abc}}$ \\
\hline$R P\left(t_{0}\right)\left(\mathrm{Pa} \mathrm{s}^{-1}\right)$ & $-56 \pm 15^{\mathrm{ab}}$ & $-38 \pm 2^{\mathrm{b}}$ & $-42 \pm 3^{\mathrm{b}}$ & $-66 \pm 3^{\mathrm{a}}$ & $-45 \pm 11^{\mathrm{b}}$ & $-55 \pm 6^{\mathrm{ab}}$ & $-43 \pm 8^{b}$ \\
\hline$R P_{\max }\left(\mathrm{Pa} \mathrm{s}^{-1}\right)$ & $73 \pm 9^{\mathrm{ab}}$ & $67 \pm 3^{\mathrm{ab}}$ & $112 \pm 8^{\mathrm{c}}$ & $63 \pm 4^{\mathrm{a}}$ & $93 \pm 15^{\mathrm{bc}}$ & $60 \pm 11^{\mathrm{a}}$ & $93 \pm 20^{\mathrm{bc}}$ \\
\hline$t_{\mathrm{RPmax}} / t_{\mathrm{E}}\left(\times 10^{-3}\right)$ & $647 \pm 13^{\mathrm{bc}}$ & $650 \pm 10^{\mathrm{bc}}$ & $672 \pm 4^{\mathrm{c}}$ & $609 \pm 9^{\mathrm{a}}$ & $648 \pm 19^{\mathrm{bc}}$ & $633 \pm 19^{\mathrm{ab}}$ & $660 \pm 14^{b c}$ \\
\hline$R P_{\min }\left(\mathrm{Pa} \mathrm{s}^{-1}\right)$ & $-107 \pm 7^{\mathrm{a}}$ & $-105 \pm 5^{\mathrm{a}}$ & $-104 \pm 28^{\mathrm{a}}$ & $-110 \pm 24^{\mathrm{a}}$ & $-135 \pm 28^{\mathrm{a}}$ & $-128 \pm 45^{\mathrm{a}}$ & $-147 \pm 14^{\mathrm{a}}$ \\
\hline$t_{\mathrm{RPmin}} / t_{\mathrm{E}}\left(\times 10^{-3}\right)$ & $801 \pm 8^{\mathrm{a}}$ & $794 \pm 6^{\mathrm{a}}$ & $823 \pm 12^{\mathrm{a}}$ & $805 \pm 4^{\mathrm{a}}$ & $799 \pm 8^{a}$ & $801 \pm 17^{\mathrm{a}}$ & $801 \pm 27^{\mathrm{a}}$ \\
\hline \multicolumn{8}{|l|}{ Viscosity changes } \\
\hline$\eta\left(t_{0}\right)(\mathrm{kPa} \mathrm{s})$ & $386 \pm 9^{\mathrm{a}}$ & $394 \pm 6^{\mathrm{a}}$ & $400 \pm 7^{\mathrm{a}}$ & $399 \pm 4^{\mathrm{a}}$ & $393 \pm 3^{\mathrm{a}}$ & $399 \pm 12^{\mathrm{a}}$ & $404 \pm 18^{\mathrm{a}}$ \\
\hline$\eta_{\min }(\mathrm{kPa} \mathrm{s})$ & $194 \pm 8^{\mathrm{a}}$ & $202 \pm 11^{\mathrm{a}}$ & $184 \pm 13^{\mathrm{a}}$ & $189 \pm 4^{\mathrm{a}}$ & $173 \pm 7^{\mathrm{a}}$ & $191 \pm 25^{\mathrm{a}}$ & $198 \pm 19^{\mathrm{a}}$ \\
\hline$t_{\eta \min } / t_{\mathrm{E}}\left(\times 10^{-3}\right)$ & $649 \pm 11^{\mathrm{ab}}$ & $684 \pm 10^{\mathrm{c}}$ & $676 \pm 8^{c}$ & $632 \pm 16^{\mathrm{a}}$ & $682 \pm 5^{c}$ & $643 \pm 9^{\mathrm{a}}$ & $668 \pm 8^{\mathrm{bc}}$ \\
\hline$\eta_{\max }(\mathrm{kPa} \mathrm{s})$ & $305 \pm 42^{\mathrm{b}}$ & $279 \pm 11^{b}$ & $450 \pm 19^{\mathrm{c}}$ & $405 \pm 5^{\mathrm{c}}$ & $224 \pm 27^{\mathrm{a}}$ & $207 \pm 16^{\mathrm{a}}$ & $218 \pm 14^{\mathrm{a}}$ \\
\hline$t_{\eta \max } / t_{\mathrm{E}}\left(\times 10^{-3}\right)$ & $722 \pm 2^{\mathrm{bc}}$ & $749 \pm 5^{\mathrm{d}}$ & $779 \pm 9^{\mathrm{e}}$ & $714 \pm 16^{\mathrm{b}}$ & $740 \pm^{\mathrm{cd}}$ & $684 \pm 20^{\mathrm{a}}$ & $708 \pm 8^{\mathrm{ab}}$ \\
\hline$R \eta_{\min }(\mathrm{kPa})$ & $-5.2 \pm 0.1^{\mathrm{ab}}$ & $-4.6 \pm 0.1^{\mathrm{b}}$ & $-5.8 \pm 0.4^{\mathrm{a}}$ & $-6.0 \pm 0.6^{\mathrm{a}}$ & $-5.8 \pm 0.5^{\mathrm{a}}$ & $-5.7 \pm 0.7^{\mathrm{a}}$ & $-5.4 \pm 0.6^{\mathrm{ab}}$ \\
\hline$t_{\mathrm{R} \eta \min } / t_{\mathrm{E}}\left(\times 10^{-3}\right)$ & $592 \pm 9^{\mathrm{abc}}$ & $610 \pm 10^{\mathrm{c}}$ & $619 \pm 8^{\mathrm{c}}$ & $576 \pm 15^{\mathrm{ab}}$ & $609 \pm 14^{\mathrm{c}}$ & $570 \pm 14^{\mathrm{a}}$ & $603 \pm 16^{b c}$ \\
\hline$R \eta_{\max }(\mathrm{kPa})$ & $16.1 \pm 4.7^{\mathrm{c}}$ & $13.6 \pm 2.4^{\mathrm{bc}}$ & $30.4 \pm 2.8^{\mathrm{d}}$ & $28.5 \pm 1.1^{\mathrm{d}}$ & $8.3 \pm 2.6^{\mathrm{ab}}$ & $3.2 \pm 0.9^{\mathrm{a}}$ & $4.6 \pm 2.1^{\mathrm{a}}$ \\
\hline$t_{\mathrm{R \eta mmax}} / t_{\mathrm{E}}\left(\times 10^{-3}\right)$ & $685 \pm 6^{\mathrm{ab}}$ & $717 \pm 7^{\mathrm{d}}$ & $727 \pm 9^{d}$ & $673 \pm 16^{\mathrm{ab}}$ & $710 \pm 1^{\mathrm{cd}}$ & $666 \pm 12^{\mathrm{a}}$ & $689 \pm 7^{\mathrm{bc}}$ \\
\hline \multicolumn{8}{|l|}{ Weight changes } \\
\hline$m(t=300 \mathrm{~s}) / m_{\mathrm{I}}-1(\%)$ & $-13.8 \pm 0.3^{\mathrm{bc}}$ & $-12.6 \pm 0.5^{\mathrm{ab}}$ & $-14.0 \pm 0.6^{\mathrm{c}}$ & $-13.5 \pm 0.4^{\mathrm{abc}}$ & $-13.4 \pm 0.5^{\mathrm{abc}}$ & $-13.8 \pm 0.6^{\mathrm{bc}}$ & $-12.4 \pm 0.5^{\mathrm{a}}$ \\
\hline
\end{tabular}

Values in the same row followed by different superscript letters are significantly different from each other $(\alpha=0.05)$

\section{Results and Discussion}

\section{Changes in Dough Volume}

Analysis of the changes in $V(t)$ occurring during the model baking (Fig. 2b) revealed two stages: (I) dough expansion and (II) crumb shrinking.

Stage (I) demonstrated the expansion of the dough volume as a result of development of its cellular structure; it was initiated at time $t_{0}$ of the baking process and lasted until time $t_{\mathrm{E}}$ when the dough achieved its maximum volume $V_{\max }$. At the beginning of baking, the analysed dough types did not differ significantly in the initial gas volume $V\left(t_{0}\right)-1 / \rho$ (Table 2).
Probably, maintenance of the constant consistency of the dough in all the analysed combinations contributed to higher homogeneity of the air bubbles entrained during dough mixing (Bellido et al. 2009).

The capacity of the dough to retain leavening gases changed during the baking process. The maximum increases in the volume $V\left(t_{\mathrm{E}}\right)-V\left(t_{0}\right)$ ranged from 0.58 to $0.74 \mathrm{~cm}^{3} \mathrm{~g}^{-1}$ and were comparable to those obtained during French bread baking (Grenier et al. 2010; Sommier et al. 2005). Enrichment of the dough with oat wholemeal resulted in increased crumb porosity, whereas the addition of carob fibre exerted an opposite effect. It can be explained by different chemical composition of used additions. Marti et al. (2014) modifying 


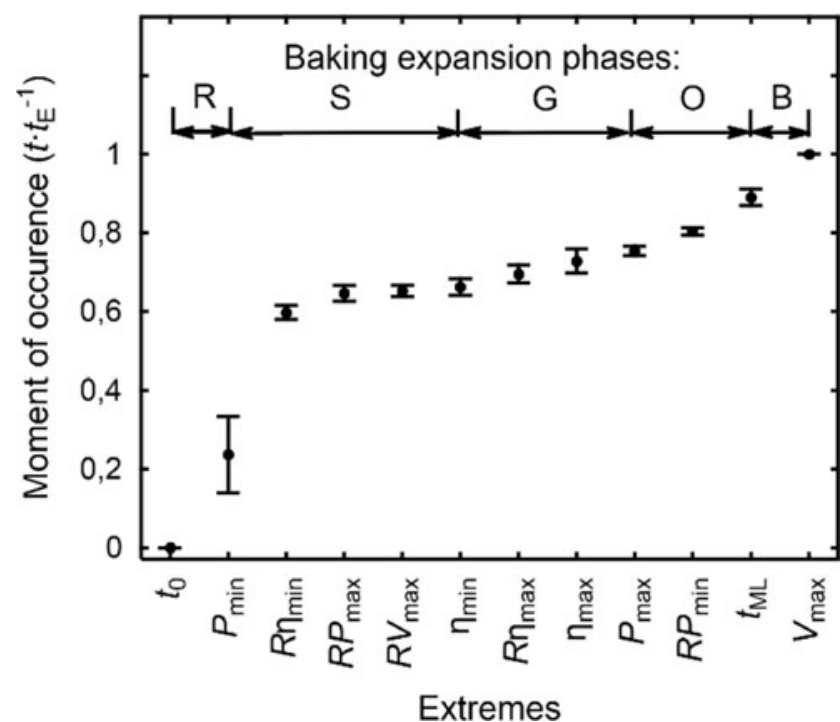

Fig. 3 Chronology of occurrence of the measured extremes within the proposed baking expansion phases of leavened dough: $R$ - Relaxation, $S$ - Softening, $G$ - Gelatinisation, $O$ - Opening, and $B$ - Boiling

enzymatically oat bran showed that the increasing of soluble to insoluble fibre ratio influenced improvement of the gas retention by bread dough.

Among the genotypic combinations, the Bombona cultivar was characterised by a significantly highest volume increase probably determined by the highest flour water absorption and gluten content (Table 1). The analysed types of dough also differed significantly in the length of the expansion time $t_{\mathrm{E}}$, which ranged from 164 to $185 \mathrm{~s}$. The longest expansion was exhibited by the Katoda wheat cultivar characterised by the most rheologically stable dough during mixing. In turn, the fibre additives used shortened the expansion stage by $5-8 \mathrm{~s}$ compared to the flour without the additives (CF). The maximum expansion rate $R V_{\max }$ (from 0.008 to $0.012 \mathrm{~cm}^{3} \mathrm{~g}^{-1} \mathrm{~s}^{-1}$ ) was achieved after at least $0.63 t_{\mathrm{E}}$. In general, the rate was proportional to the maximum dough expansion $V\left(t_{\mathrm{E}}\right)-V\left(t_{0}\right)$, and the moment of its appearance $t_{\mathrm{RV} \max }$ was delayed together with the prolongation of $t_{\mathrm{E}}$.

Stage (II) occurred during baking time $t>t_{\mathrm{E}}$ and demonstrated reduction of the bread crumb volume as a result of thermosetting of its cellular structure. The intensity of shrinking expressed by crumb volume loss caused by 100 -s baking after the end of expansion $V\left(t_{\mathrm{E}}+100 \mathrm{~s}\right) / V\left(t_{\mathrm{E}}\right)-1$ varied from -15.6 to $-18.9 \%$. The Finezja cultivar was characterised by the highest shrinking rate probably due to the lowest flour water absorption (Table 1). The highest shrinking dynamics $R V_{\text {min }}$ was reported for the blend of the commercial flour with oat wholemeal, which concurrently exhibited the highest expansion dynamics $R V_{\max }$. Comparison of $R V_{\min }$ and $R V_{\max }$ revealed an approximately seven-fold lower shrinking rate relative to the expansion rate. However, the analysed types of dough differed more significantly in terms of the $t_{\mathrm{RVmin}}$. The $t_{\mathrm{RVmin}} / t_{\mathrm{E}}$ values ranged from 1.23 to 1.35 and indicated an impact of the higher gluten content or addition of carob fibre on the delayed crumb shrinking.

The rate of crumb shrinking during baking and the background of the phenomenon have seldom been studied so far and the analysis of volume changes has been typically limited to expansion stage, also called the oven rise (Grenier et al. 2010). During baking at $180{ }^{\circ} \mathrm{C}$, Chevallier et al. (2002) observed that the thickness of biscuits during the 100 -second shrinking period decreased from 6.5 to $5.0 \mathrm{~mm}$, i.e. by ca. $23 \%$. The shrinking phenomenon was also observed during baking of yeast-leavened bread dough, where a decrease in the dough section (Sommier et al. 2005) as well as in loaf height (Pérez-Nieto et al. 2010) was recorded. The shrinking phenomenon caused 20 and $14 \%$ reduction, respectively, compared with the increases in the expansion stage.

One of the major transformations associated with baking is intensive loss of water leading to crumb thermosetting (Vanin et al. 2013) and loaf shrinking in the baking process. The results of this study (Table 2) indicate that the loss in the dough weight $m(t=300 \mathrm{~s}) / m_{\mathrm{I}}-1$ reached $14 \%$. Comparable ranges of dough water loss were noted in the aforementioned papers by Sommier et al. (2005) and Pérez-Nieto et al. (2010). This may indicate that the drying rate should be regarded as one of the main causes of the shrinking phenomenon. The additional reason for crumb shrinkage is the steady pressure decline at end of baking (Fig. 2c), which was also reported by Grenier et al. (2010). The pressure drops due to the rupture of the gas bubbles and the increase in connectivity between them (Babin et al. 2006). At this stage of baking, the dough matrix forming bubble walls was not fully hardened; hence, the decrease in the pressure may also contribute to crumb shrinking due to partial collapse of the bubbles.

\section{Changes in Dough Pressure}

Pressure changes $P(t)$ (Fig. 2c) had a more complex course than that of $V(t)$. Based on the changes, four phases were distinguished: (I) stress relaxation, (II) pressure rise, (III) cell opening, and (IV) boiling.

In phase (I), from $t_{0}$ to $t_{\mathrm{Pmin}}$, there was a mild decrease in pressure, whose rate declined along with approaching $t_{\mathrm{Pmin}}$. This course may indicate a process of relaxation of stress produced in time $t<t_{0}$ by compression of the dough disc to reach the thickness $H$. Concurrently, the temperature rise was accompanied by softening of the dough gluten matrix and expansion of gas accumulated in the bubbles $V\left(t_{0}\right)-1 / \rho$ as well as diffusion of $\mathrm{CO}_{2}$ from the liquid phase into the bubbles. Since these two contrasting processes overlapped, the moment of occurrence of a minimum pressure $t_{\mathrm{Pmin}}$ in the analysed experimental combinations differed more strongly from the $P_{\min }$ (Table 2). In comparison to the genotypic combinations, the technological variants $(\mathrm{CF}, \mathrm{CF}+\mathrm{C}$, and $\mathrm{CF}+\mathrm{O})$ were characterised by, on average, a two-fold shorter time of 
dough heating until achievement of minimum pressure. This may indicate that the lower content of gluten and inferior rheological properties of dough (Table 1) contribute to $t_{\text {Pmin }}$ shortening, probably due to the shorter relaxation times of the lower quality dough (Patel and Chakrabarti-Bell 2013).

In phase (II), from $t_{\mathrm{Pmin}}$ to $t_{\mathrm{Pmax}}$, the dough pressure began to increase gradually. A temperature rise up to $40-50{ }^{\circ} \mathrm{C}$ accelerated $\mathrm{CO}_{2}$ desolubilisation from the liquid state (Grenier et al. 2010) and intensified thermal gas expansion in the gas bubbles. These two processes combined with the dough retention capacity caused differences in the rates of the pressure rise. The flour-oat wholemeal blend had the highest $R P_{\max }$ value, which was nearly two-fold higher than the lowest value noted for the Katoda cultivar. The $R P_{\max }$ was proportional to $R V_{\max }$, which was supported by the positive correlations between these indices. The $R P_{\max }$ value increased along with the delay of its occurrence $t_{\text {RPmax }}$. Next, the dynamics of pressure growth was gradually slower until occurrence of a maximum pressure peak $\left(t_{\mathrm{Pmax}}\right)$. The $t_{\mathrm{Pmax}}$ for the analysed combinations was in a very narrow range of the baking time, i.e. from 0.73 to $0.77 t_{\mathrm{E}}$. The commercial flour with and without the carob fibre additive was characterised by a significantly lower $P_{\max }$ than that in the other combinations. By extending the proving period from 30 to $47 \mathrm{~min}$., Grenier et al. (2010) obtained shortened $t_{\mathrm{Pmax}}$ and reduced $P_{\max }$. They recorded maximum pressures $P_{\max }$ in the range from 0.4 to $1.0 \mathrm{kPa}$, which were several times lower than the values presented in Table 2 (from 2.8 to $3.7 \mathrm{kPa}$ ). This could be explained by the fact that Grenier et al. (2010) performed their measurements on substantially larger objects using dough sticks of $40 \mathrm{~mm}$ in diameter. At the same viscosity and dough expansion rate, pressure $P(t)$ being the driving force of expansion is inversely proportional to the width of gap $H$ between the heating plates. Therefore, by doubling $(2 H)$ the thickness of the dough disc, a two-fold lower pressure $P(t)$ is produced in expanded dough (Miś and Rusinek 2004).

In phase (III), from $t_{\mathrm{Pmax}}$ to $t_{\mathrm{ML}}$, a sharp decline in the dough pressure was noted. The dynamics of this phase expressed with the $R P_{\text {min }}$ parameter reached an average value of $-119 \mathrm{~Pa} \mathrm{~s}^{-1}$, which was almost 1.5 -fold higher than $R P_{\max }$. However, the experimental combinations did not exert a significant effect on the differences in $R P_{\min }$ and $t_{\mathrm{RPmin}}$. As reported by Singh and Bhattacharya (2005), the phenomenon of opening of the gas cells is directly associated with release of gas from the cells, which leads to reduction of pressure. Similar results were reported for reacting polyurethane foams, where the cell opening was detected by a sudden drop in normal force (Neff and Macosko 1996).

At the beginning of phase (IV), $t=t_{\mathrm{ML}}$, the pressure decline $\left(R P\left(t_{\mathrm{ML}}\right)=0\right)$ was inhibited by water boiling. In this baking phase, the temperature of the dough, in particular in the peripheral zones of the loaf, reached the water boiling point (Wang and Sun 1999). The amount of released water vapour was sufficient to compensate for the volume of gas lost through cell openings. When $t>t_{\mathrm{ML}}$, the intensity of water boiling increased; consequently, the dough pressure was rising again until the end of expansion $t_{\mathrm{E}}$, when the second pressure peak was evident (Fig. 1c). However, the value and location of this peak was not estimated accurately for reasons described in the section "Statistical Analyses". In the final step of baking (crumb shrinking), the gas pressure in the crumb declined monotonically and was finally equal to the ambient pressure.

\section{Changes in Dough Viscosity}

Regardless of the flour type and quality, the initial dough viscosity $\eta\left(t_{0}\right)$ exhibited the same level (Table 2$)$, which was related to the procedure of mixing dough with constant consistency (section "Preparation of Dough"). The analysis of the changes in dough viscosity (Fig. 2d) carried out in the baking time range from $t_{0}$ to approx. $0.9 t_{\mathrm{E}} \sim t_{\mathrm{ML}}$ revealed three phases: (I) gluten matrix softening, (II) starch gelatinisation and protein aggregation, and (III) starch gel softening.

Phase (I) began at $t_{0}$, when the baking test was initiated, and finished at $t_{\text {nmin }}$, when due to the rise in the dough temperature its viscosity dropped and reached the minimum value $\eta_{\min }$. The duration of this phase (Table 2) ranged from $0.63 t_{\mathrm{E}}$ (Finezja) to $0.68 t_{\mathrm{E}}$ (Bombona). Fortification of the dough with carob fibre or oat wholemeal prolonged phase (I) by $0.03 t_{\mathrm{E}}$. As a result of thermal softening, the viscosity of the dough was almost two-fold lower, irrespective of the type of the dough. The highest dynamics of the viscosity decline was noted at $(0.05-0.07) t_{\mathrm{E}}$ before the end of this phase. Among the combinations tested, carob fibre was the most potent factor reducing the dynamics. Phase (I) was also observed by Singh and Bhattacharya (2005) and Ahmed (2015). They reported gradual reduction of the dynamic storage and loss moduli accompanying the rise in dough temperature in the range of 25- $60{ }^{\circ} \mathrm{C}$.

In phase (II), $t_{\eta \min }<t<t_{\eta \max }$, the temperature of the dough was so high that starch granules began to swell, achieving a three- to four-fold increase in their volume, and gluten proteins formed additional cross-links (Ahmed 2015; Rouillé et al. 2010). In consequence, these transformations led to a rapid increase in viscosity, and its maximum was reached considerably earlier by the high-gluten cultivars (Zebra, Katoda and Bombona), i.e. as early as within (0.04-0.06) $t_{\mathrm{E}}$ after the beginning of starch gelatinisation. Probably, the gluten matrix that covers starch granules highly restricted water access, which may have led to shortening of the gelatinisation process. Simultaneously, the lower gelatinisation degree of the starch may have resulted in significantly lower maximum gelatinisation viscosities $\eta_{\max }$ and rates $R \eta_{\max }$ in the high-gluten cultivars, compared to the other varieties. Similar trends in viscosity were reported by Ragaee and Abdel-Aal (2006), who investigated pasting properties of soft 
and hard wheat flour using a Rapid Visco Analyser. Compared to the hard type, soft wheat, characterised by lower gluten content, exhibited a nearly two-fold higher viscosity peak. Additionally, the soft wheat in comparison with the hard one is less susceptible to mechanical damage of starch granules during milling. The lower the degree of starch damage, the higher the viscosity peak during gelatinisation (Liu et al. 2014). The research of Dreese et al. (1988) demonstrated that an increase in viscosity of dough made of vital gluten and native starch observed during heating at temperatures from 55 to $75^{\circ} \mathrm{C}$ was proportional to the starch content in the dough. The significant effect of the starch concentration on gel viscosity was also emphasised in the investigations carried out by Keetels et al. (1996). The analysed fibre additives influenced the course of gelatinisation in an opposite manner. Mainly due to the absence of starch in its composition, carob fibre reduced the gelatinisation increase $R \eta_{\max }$, whereas oat wholemeal, which is rich in this component, nearly doubled it.

Phase (III), $t_{\eta \max }<t<t_{\mathrm{ML}}$, comprised the second step of gelatinisation, during which disruption and leaching of the amylose component of starch granules and melting of high stability amylopectin crystallites were observed (Ahmed et al. 2013). These transformations led to a decrease in dough viscosity (Fig. 2d). The course of the viscosity changes at the end stage of baking $t>t_{\mathrm{ML}}$ was not analysed for reasons presented in section "Statistical Analyses".

\section{Interrelation of the Determined Phases in Volume, Pressure, and Viscosity Changes as a Useful Tool for Explanation of Baking Process}

The volume, pressure, and viscosity changes described above were used for elucidation of the mechanism of dough expansion in baking process.

In the baking expansion stage, $t_{0}<t<t_{\mathrm{E}}$, the analysis of changes in pressure $P(t)$ and viscosity $\eta(t)$ and their dynamics revealed the following five phases: stress relaxation $(\mathrm{R})$, gluten matrix softening $(S)$, starch gelatinisation $(G)$, opening of gas bubbles (O) and boiling of water in dough (B). The expansion phases are listed chronologically in Fig. 3, whereas Table 3 presents the effect of the studied fibre-rich additions and wheat cultivars on the differentiation of the duration and contribution of the specified phases to dough expansion $\left(V\left(t_{\mathrm{E}}\right)-\right.$ $\left.V\left(t_{0}\right)\right)$.

The dough relaxation phase (R), $t_{0}<t<t_{\mathrm{Pmin}}$, is the first baking phase during which a slight decline in pressure and a viscosity decrease are observed concurrently. A characteristic feature of the relaxation phase at its initial course is the distinctly higher rate of drop in pressure rather than viscosity. The low pressure of leavening gases relative to the high dough viscosity results in low dough expansion rates. The results of these investigations (Table 3 ) showed that these increases were in the range from 0.3 to $3.0 \%$. Dough with higher gluten content (genotypic combinations) was characterised by over two-fold longer relaxation phases and 10-fold higher volume expansion in comparison with the fibre-enriched dough $(\mathrm{CF}+$ $\mathrm{C}$ and $\mathrm{CF}+\mathrm{O}$ ).

In the gluten matrix softening phase (S), $t_{\mathrm{Pmin}}<t<t_{\eta \min }$, there is a substantial decline in viscosity accompanied by a gradual pressure rise. The overlapping of these two opposite transformations leads to a dynamic increase in the expansion rate. In this phase, not only the expansion rate $R V_{\max }$, but also the viscosity decline rate $R \eta_{\min }$ and the pressure rise rate $R P_{\max }$ exhibit extreme values. Given the significantly high dough expansion rate, phase $\mathrm{S}$ can also be regarded as a phase of rapid development of the dough cellular structure or as an oven rise (Grenier et al. 2010). The presented results indicate that completion of phase $\mathrm{S}$ for the analysed combinations was achieved at a similar expansion time, i.e. approx. $0.66 t_{\mathrm{E}}$, whereas the length of phases $\mathrm{R}$ and $\mathrm{S}$ differed significantly depending on the type of dough. Thermally induced physical transformations leading to gradual mechanical weakening of the dough gluten matrix facilitate dough expansion in phases $\mathrm{R}$ and $\mathrm{S}$. Hence, the beginning of the pressure rise had a significant impact on the differentiation of the volume increase, which ranged from 44 to $66 \%$. Dough with a longer softening phase (S) was also characterised by higher expansion rates. In their analysis of the softening phase, Singh and Bhattacharya (2005) observed a slow decline in the storage modulus and a gradual increase in normal force (pressure); however, they did not report a significant increase in dough expansion. They noted dough expansion only at the beginning of the starch gelatinisation phase $(\mathrm{G})$. A probable cause of the failure to detect expansion in the softening phase was the use of the autotension adjustment to monitor changes in the gap width $(\Delta \mathrm{L})$ as a rise in dough. It proved to be useless for examination of the volume changes occurring during the softening phase. In contrast, the investigations conducted by Grenier et al. (2010) showed that the oven rise occurred primarily in the softening phase, but the successive baking phases did not cause a substantial volume increase.

The starch gelatinisation phase $(\mathrm{G}), t_{\eta \min }<t<t_{\mathrm{P} \max }$, is characterised by a significant increase in dough viscosity resulting from the starch gelatinisation and protein aggregation process, which starts at a temperature of $55-60{ }^{\circ} \mathrm{C}$ depending on the dough chemical composition and water content (Chevallier et al. 2000; Vanin et al. 2013). During the gelatinisation phase, the viscosity rise rate and viscosity exhibit maximum values. In response to the increasing dough resistance, bubble gas pressure increases, and the rate of the increase declines during phase $\mathrm{G}$, which results in a gradual slowing-down of the expansion rate. In terms of duration, the gelatinisation phase was the shortest of the analysed expansion phases and lasted $0.09 t_{\mathrm{E}}$ on average. However, due to the still high expansion rate during the gelatinisation, this phase had an average $22 \%$ contribution to the dough expansion. The 
Table 3 Effect of experimental combinations on duration of baking expansion phases and their contribution to volume rise (\%)

\begin{tabular}{|c|c|c|c|c|c|c|c|}
\hline & \multicolumn{7}{|c|}{ Experimental combinations } \\
\hline & $\mathrm{CF}$ & $\mathrm{CF}+\mathrm{C}$ & $\mathrm{CF}+\mathrm{O}$ & FIN & $\mathrm{BOM}$ & KAT & ZEB \\
\hline \multicolumn{8}{|l|}{ Duration of phases } \\
\hline Relaxation (R) & $14.0 \pm 1.0^{\mathrm{a}}$ & $14.9 \pm 1.0^{\mathrm{a}}$ & $12.2 \pm 1.4^{\mathrm{a}}$ & $27.4 \pm 1.4^{\mathrm{b}}$ & $33.5 \pm 1.9^{c}$ & $28.5 \pm 3.7^{\mathrm{b}}$ & $35.2 \pm 1.5^{\mathrm{c}}$ \\
\hline Softening (S) & $50.9 \pm 1.3^{\mathrm{c}}$ & $53.5 \pm 1.1^{\mathrm{cd}}$ & $55.4 \pm 1.3^{\mathrm{d}}$ & $35.8 \pm 2.3^{\mathrm{b}}$ & $34.7 \pm 1.4^{\mathrm{ab}}$ & $35.8 \pm 3.2^{\mathrm{b}}$ & $31.6 \pm 0.7^{\mathrm{a}}$ \\
\hline Gelatinisation $(\mathrm{G})$ & $10.3 \pm 1.2^{\mathrm{cd}}$ & $4.9 \pm 1.1^{\mathrm{a}}$ & $9.3 \pm 1.0^{\mathrm{bcd}}$ & $12.9 \pm 1.3^{\mathrm{d}}$ & $6.1 \pm 0.1^{\mathrm{ab}}$ & $11.9 \pm 1.2^{\mathrm{cd}}$ & $8.7 \pm 3.7^{\mathrm{abc}}$ \\
\hline Opening $(\mathrm{O})$ & $13.1 \pm 0.9^{\mathrm{b}}$ & $16.6 \pm 0.3^{\mathrm{cd}}$ & $14.2 \pm 1.5^{\mathrm{bc}}$ & $11.6 \pm 1.4^{\mathrm{ab}}$ & $17.7 \pm 1.5^{\mathrm{d}}$ & $9.5 \pm 2.2^{\mathrm{a}}$ & $12.8 \pm 1.3^{\mathrm{b}}$ \\
\hline Boiling (B) & $11.7 \pm 0.6^{\mathrm{abc}}$ & $10.0 \pm 0.4^{\mathrm{ab}}$ & $8.9 \pm 1.5^{\mathrm{ab}}$ & $12.2 \pm 1.4^{\mathrm{bc}}$ & $8.1 \pm 0.9^{\mathrm{a}}$ & $14.3 \pm 2.8^{\mathrm{c}}$ & $11.6 \pm 2.2^{\mathrm{abc}}$ \\
\hline \multicolumn{8}{|c|}{ Contribution of phases to volume rise } \\
\hline Relaxation (R) & $0.7 \pm 0.2^{\mathrm{a}}$ & $0.4 \pm 0.1^{\mathrm{a}}$ & $0.3 \pm 0.1^{\mathrm{a}}$ & $2.4 \pm 0.3^{\mathrm{b}}$ & $2.5 \pm 1.0^{\mathrm{b}}$ & $2.2 \pm 1.0^{\mathrm{b}}$ & $3.4 \pm 0.5^{\mathrm{b}}$ \\
\hline Softening (S) & $56.7 \pm 4.9^{\mathrm{bc}}$ & $65.8 \pm 4.9^{\mathrm{c}}$ & $60.0 \pm 3.5^{\mathrm{bc}}$ & $43.9 \pm 6.3^{\mathrm{a}}$ & $58.0 \pm 2.9^{\mathrm{bc}}$ & $44.7 \pm 1.0^{\mathrm{a}}$ & $52.5 \pm 2.8^{\mathrm{ab}}$ \\
\hline Gelatinisation $(\mathrm{G})$ & $23.2 \pm 3.7^{\mathrm{bc}}$ & $11.6 \pm 3.4^{\mathrm{a}}$ & $21.5 \pm 3.0^{\mathrm{abc}}$ & $31.5 \pm 4.6^{\mathrm{c}}$ & $16.2 \pm 1.1^{\mathrm{ab}}$ & $30.0 \pm 2.6^{\mathrm{c}}$ & $22.5 \pm 8.5^{\mathrm{bc}}$ \\
\hline Opening $(\mathrm{O})$ & $16.1 \pm 1.5^{\mathrm{ab}}$ & $20.1 \pm 1.5^{\mathrm{ab}}$ & $16.2 \pm 1.3^{\mathrm{ab}}$ & $17.3 \pm 1.1^{\mathrm{ab}}$ & $21.9 \pm 3.0^{\mathrm{b}}$ & $15.7 \pm 3.4^{\mathrm{a}}$ & $18.1 \pm 4.2^{\mathrm{ab}}$ \\
\hline Boiling (B) & $3.4 \pm 0.6^{\mathrm{ab}}$ & $2.1 \pm 0.3^{\mathrm{a}}$ & $2.1 \pm 0.8^{\mathrm{a}}$ & $5.0 \pm 1.5^{\mathrm{bc}}$ & $1.4 \pm 0.3^{\mathrm{a}}$ & $7.4 \pm 2.4^{\mathrm{c}}$ & $3.5 \pm 1.2^{\mathrm{ab}}$ \\
\hline
\end{tabular}

Values in the same row followed by different superscript letters are significantly different from each other $(\alpha=0.05)$

shortest phase G duration and, simultaneously, the lowest volume increments were characteristic for the carob-fibreenriched dough $(\mathrm{CF}+\mathrm{C})$ and the dough made of wheat with the highest gluten content (Bombona). The impact of this phase on dough expansion was two-fold higher in the case of the Finezja and Katoda cultivars, characterised by substantially lower gluten content.

The opening phase $(\mathrm{O}), t_{\mathrm{P} \max }<t<t_{\mathrm{ML}}$, begins at the time of a rapid pressure decrease and indicates initiation of the cell opening phenomenon. In this phase, the dough structure with separate gas bubbles is transformed into a crumb structure with interconnected bubbles (Singh and Bhattacharya 2005). Leavening gases are readily released into the environment through the openings formed in the bubble walls. The cell opening is a result of initiation of second gelatinisation phase leading to starch gel softening (Ahmed et al. 2013). As a result of the gel softening, the gas bubble walls lose their strength and become ruptured. However, the bubble structure of the crumb does not collapse because, despite its substantial decrease, the gas pressure is still sufficiently high to overcome the crumb shrinking force and maintain its very slow expansion. Consequently, despite the sudden drop in dough pressure and viscosity, the course of phase $\mathrm{O}$ contributed to further dough expansion by $18 \%$, on average. The carob-fibreenriched dough and the dough with the highest gluten content (Bombona) were characterised by the longest duration of phase $\mathrm{O}$ resulting in 20 and $22 \%$ increases in dough volume, respectively.

The boiling phase (B), $t_{\mathrm{ML}}<t<t_{\mathrm{E}}$, begins when the temperature in the peripheral dough zone reaches the water boiling point. Released water vapour gradually raises dough pressure, which prevents collapse of the crumb and results in a slight volume increase, on average by $4 \%$. In this phase, the water boiling intensity fully compensates for the loss of gases, which are released into the environment through bubble wall openings. After completion of the expansion phase, $t>t_{\mathrm{E}}$, the gas pressure begins to decline and the crumb shrinks. A characteristic feature of phases $\mathrm{O}$ and $\mathrm{B}$ is the considerable loss of dough water (Wang and Sun 1999; Vanin et al. 2013). Changes in the water content are one of the basic transformations leading to final thermosetting of the crumb cellular structure.

\section{Conclusions}

The developed method for identification of baking expansion phases allowed precise determination of the chronology of physical, chemical, and structural transformations that lead to transition of viscous-liquid dough into solid and cellular-structured crumb of the bakery product. The baking expansion was divided into five phases. The first phase is stress relaxation (R) characterised by a very low dough expansion ( $2 \%$ ). During the next phase of gluten matrix softening (S), the decreasing viscosity is accompanied by a gradual pressure increase and, hence, a substantial volume increase $(\sim 54 \%)$. At the phase of starch gelatinisation and protein aggregation $(\mathrm{G})$, the decreasing expansion rate $(\sim 22 \%)$ is noted. During the gas bubble opening $(\mathrm{O})$ phase, the thermal weakening of the starch gel consistency results in a rapid pressure decline and a further slowing-down of the dough expansion ( $18 \%)$. The final expansion phase, contributing to a ca. $4 \%$ rise in the volume, is boiling of water in dough (B), which ends when the pressure of released vapour is low enough to prevent crumb shrinking. 
The used fibre enrichment and wheat cultivars differentiated significantly the course of baking expansion phases. Carob-fibre enrichment of the dough extended phases S and $\mathrm{O}$ and increased the contribution of these phases to expansion at the cost of phase G. A similar impact on the expansion phases was found for the Bombona wheat cultivar, which exhibits the highest gluten content. In contrast, the Finezja and Katoda cultivars, which exhibit a lower gluten level, were characterised by an approximately two-fold higher impact of phase $\mathrm{G}$ on the dough expansion. The results show that the proposed identification of baking expansion phases of leavened dough can substantially enhance the assessment of the baking quality of raw materials and bakery additives. Among other applications, optimisation of parameters of baking process through the appropriate shaping of the course of individual expansion phases can result in further improving of the quality of bakery products.

\section{Compliance with Ethical Standards}

Conflict of Interest The authors declare that they have no conflict of interest.

Open Access This article is distributed under the terms of the Creative Commons Attribution 4.0 International License (http:// creativecommons.org/licenses/by/4.0/), which permits unrestricted use, distribution, and reproduction in any medium, provided you give appropriate credit to the original author(s) and the source, provide a link to the Creative Commons license, and indicate if changes were made.

\section{References}

Ahmed, J. (2015). Effect of barley $\beta$-glucan concentrate on oscillatory and creep behavior of composite wheat flour dough. Journal of Food Engineering, 152, 85-94.

Ahmed, J., Almusallam, A. S., Al-Salman, F., AbdulRahman, M. H., \& Al-Salem, E. (2013). Rheological properties of water insoluble date fiber incorporated wheat flour dough. LWT-Food Science and Technology, 51(2), 409-416.

Babin, P., Della Valle, G., Chiron, H., Cloetens, P., Hoszowska, J., Pernot, P., Réguerre, A. L., Salvo, L., \& Dendievel, R. (2006). Fast X-ray tomography analysis of bubble growth and foam setting during breadmaking. Journal of Cereal Science, 43(3), 393-397.

Bellido, G. G., Scanlon, M. G., \& Page, J. H. (2009). Measurement of dough specific volume in chemically leavened dough systems. Journal of Cereal Science, 49(2), 212-218.

Besbes, E., Bail, A., \& Seetharaman, K. (2014). Effect of baking conditions on properties of starch isolated from bread crumbs: pasting properties, iodine complexing ability, and X-ray patterns. Food and Bioprocess Technology, 7(12), 3407-3415.

Chevallier, S., Colonna, P., Della Valle, G., \& Lourdin, D. (2000). Contribution of major ingredients during baking of biscuit dough systems. Journal of Cereal Science, 31(3), 241-252.

Chevallier, S., Della Valle, G., Colonna, P., Broyart, B., \& Trystram, G. (2002). Structural and chemical modifications of short dough during baking. Journal of Cereal Science, 35(1), 1-10.

Chin, N. L., \& Campbell, G. M. (2005). Dough aeration and rheology: part 2. Effects of flour type, mixing speed and total work input on aeration and rheology of bread dough. Journal of the Science of Food Agriculture, 85(13), 2194-2202.

Dreese, P. C., Faubion, J. M., \& Hoseney, R. C. (1988). Dynamic rheological properties of flour, gluten and gluten-starch doughs. I. Temperature dependent changes during heating. Cereal Chemistry, 65(4), 384-352.

Elmehdi, H. M., Page, J. H., \& Scanlon, M. G. (2004). Ultrasonic investigation of the effect of mixing under reduced pressure on the mechanical properties of bread dough. Cereal Chemistry, 81(4), 504 510.

Fessas, D., \& Schiraldi, A. (2000). Starch gelatinization kinetics in bread dough. DSC investigations on 'simulated' baking processes. Journal of Thermal Analysis and Calorimetry, 61(2), 411-423.

Grenier, D., Le Ray, D., \& Lucas, T. (2010). Combining local pressure and temperature measurements during bread baking: insights into crust properties and alveolar structure of crumb. Journal of Cereal Science, 52(1), 1-8.

ICC. (1992). Method for using the Brabender farinograph. Vienna: International Association for Cereal Science and Technology. ICC Standard No. 115/1.

ICC. (1994). Determination of wet gluten quantity and quality (gluten index ac. to perten) of whole wheat meal and wheat flour (Triticum aestivum). Vienna: International Association for Cereal Science and Technology. ICC Standard No. 155.

ICC. (1995). Determination of the "falling number" according to Hagberg-Perten as a measure of the degree of alpha-amylase activity in grain and flour. Vienna: International Association for Cereal Science and Technology. ICC Standard No. 107/1.

Keetels, C., van Vliet, T., \& Walstra, P. (1996). Gelation and retrogradation of concentrated starch systems. 1. Gelation. Food Hydrocolloids, 10(3), 343-353.

Liu, C., Li, L. M., Hong, J., Zheng, X. L., Bian, K., Sun, Y., \& Zhang, J. (2014). Effect of mechanically damaged starch on wheat flour, noodle and steamed bread making quality. International Journal of Food Science and Technology, 49(1), 253-260.

Marti, A., Bottega, G., Casiraghi, M. C., Faoro, F., Iametti, S., \& Pagani, M. A. (2014). Dietary fibre enzymatic treatment: a way to improve the rheological properties of high-fibre-enriched dough. International Journal of Food Science and Technology, 49(1), 305-307.

Miś, A. (2011). Interpretation of mechanical spectra of carob fibre and oat wholemeal-enriched wheat dough using non-linear regression models. Journal of Food Engineering, 102(4), 369-379.

Miś, A., \& Dziki, D. (2013). Extensograph curve profile model used for characterizing the impact of dietary fibre on wheat dough. Journal of Cereal Science, 57(3), 471-479.

Miś, A., \& Rusinek, R. (2004). Measurement of mechanical properties of gluten membranes during thermal treatment (in Polish). Acta Agrophysica, 4(2), 419-429.

Mondal, A., \& Datta, A. K. (2008). Bread baking e a review. Journal of Food Engineering, 86(4), 465-474.

Nawrocka, A., Szymańska-Chargot, M., Miś, A., Ptaszyńska, A. A., Kowalski, R., Waśko, P., \& Gruszecki, W. I. (2015). Influence of dietary fibre on gluten proteins structure - a study on model flour with application of FT-Raman spectroscopy. Journal of Raman Spectroscopy, 46(3), 309-316.

Nawrocka, A., Szymańska-Chargot, M., Miś, A., Kowalski, R., \& Gruszecki, W. I. (2016). Raman studies of gluten proteins aggregation induced by dietary fibres. Food Chemistry, 194, 86-94.

Neff, R. A., \& Macosko, C. W. (1996). Simultaneous measurement of viscoelastic changes and cell opening during processing of flexible polyurethane foam. Rheologica Acta, 35(6), 656-666.

Patel, M. J., \& Chakrabarti-Bell, S. (2013). Flour quality and dough elasticity: dough sheetability. Journal of Food Engineering, 115(3), 371-383. 
Pérez-Nieto, A., Chanona-Pérez, J. J., Farrera-Rebollo, R. R., GutiérrezLópez, G. F., Alamilla-Beltrán, L., \& Calderón-Domínguez, G. (2010). Image analysis of structural changes in dough during baking. LWT - Food Science and Technology, 43(3), 535-543.

Ragaee, S., \& Abdel-Aal, E.-S. M. (2006). Pasting properties of starch and protein in selected cereals and quality of their food products. Food Chemistry, 95(1), 9-18.

Rouillé, J., Chiron, H., Colonna, P., Della Valle, G., \& Lourdin, D. (2010). Dough/crumb transition during French bread baking. Journal of Cereal Science, 52(2), 161-169.

Schofield, J. D., Bottomley, R. C., Timms, M. F., \& Booth, M. R. (1983). The effect of heat on wheat gluten and the involvement of sulphydryl-disulphide interchange reactions. Journal of Cereal Science, 1(4), 241-253.

Singh, H. (2005). A study of changes in wheat protein during bread baking using SE-HPLC. Food Chemistry, 90(1-2), 247-250.

Singh, A. P., \& Bhattacharya, M. (2005). Development of dynamic modulus and cell opening of dough during baking. Journal of Texture Studies, 36(1), 44-67.
Sommier, A., Chiron, H., Colonna, P., Della Valle, G., \& Rouille, J. (2005). An instrumented pilot scale oven for the study of French bread baking. Journal of Food Engineering, 69(1), 97-106.

Vanin, F. M., Michon, C., Trystram, G., \& Lucas, T. (2010). Simulating the formation of bread crust in a DMTA rheometer. Journal of Cereal Science, 51(3), 277-283.

Vanin, F. M., Michon, C., \& Lucas, T. (2013). Effect of the drying rate on the complex viscosity of wheat flour dough transforming into crust and crumb during baking. Journal of Cereal Science, 58(2), 290297.

Wagner, M. J., Lucas, T., Le Ray, D., \& Trystram, G. (2007). Water transport in bread during baking. Journal of Food Engineering, 78(4), 1167-1173.

Wang, F. C., \& Sun, X. S. (1999). Thermal expansion of flour water dough measured with a dynamic mechanical analyzer. Cereal Chemistry, 76(1), 87-91.

Wieser, H. (2007). Chemistry of gluten proteins. Food Microbiology, 24(2), 115-119. 